\title{
Desempenho fiscal e eleições no Brasil: uma análise comparada dos governos municipais ${ }^{1}$
}

\author{
Pedro Cavalcante \\ Universidade de Brasília / Programa de Pós-Graduação em Administração \\ Brasilia / DF - Brasil
}

\begin{abstract}
O objetivo é analisar a relação entre a gestão fiscal e o instituto da reeleição de prefeitos no Brasil sob múltiplas dimensões e numa perspectiva temporal abrangente (1997 a 2012). A pesquisa testa duas hipóteses principais: i) o prefeito em primeiro mandato apresenta um melhor desempenho fiscal devido à possibilidade de reeleição; ii) o prefeito que apresenta um melhor desempenho fiscal tende a ser premiado com sua reeleição. Os resultados dos modelos de regressão multivariada refutam a hipótese de que a expectativa de reeleição geraria desempenhos fiscais distintos. Quanto à segunda, os esforços em elevar os tributos interferem negativamente nas chances de sucesso eleitoral, enquanto o eleitor premia aquele que mais investe.
\end{abstract}

Palavras-chave: desempenho fiscal; governos municipais; reeleição; comportamento eleitoral.

El desempeño fiscal y elecciones en Brasil: un análisis comparativo de los gobiernos municipales El objetivo es analizar la relación entre el desempeño fiscal y la reelección de alcaldes en Brasil bajo múltiples dimensiones y un horizonte temporal amplio (1997 hasta 2012). El estudio pone a prueba dos hipótesis principales: i) el alcalde en primer plazo tiene un mejor desempeño fiscal debido a la posibilidad de la reelección; ii) el alcalde que tiene un mejor desempeño fiscal tiende a ser recompensado por el electorado con su reelección. Los resultados de los modelos de regresión multivariante refutan la hipótesis de que la reelección esperada generaría desempeño fiscal diferente. Los esfuerzos del alcalde para aumentar los impuestos interfieren negativamente en las posibilidades de éxito electoral, mientras que el elector recompensas aquellos que mais invierten.

Palabras clave: desempeño fiscal; gobiernos municipales; reelección; comportamiento electoral.

DOI: http://dx.doi.org/10.1590/0034-7612146623

${ }^{1}$ Gostaria de agradecer aos pareceristas (blind reviewers) pelas suas críticas e sugestões que contribuíram para o aperfeiçoamento deste artigo. 
Fiscal performance and elections in Brazil: a comparative analysis of local governments The paper's goal is to analyze the relationship between fiscal performance and re-election for mayors in Brazil based on multiple dimensions and a comprehensive time period (1997 to 2012). The research tests two main hypothesis: i) the first-term mayor tends to achieve a better fiscal performance due to the chance of re-election; ii) the mayor who has a better performance tends to be rewarded by the voters with his re-election. The multivariate regression models refute the hypothesis that the expected re-election would generate different fiscal performance. Regarding the second, the efforts to raise tax negatively affect in his/hers likelihood of electoral success, whereas the electorate rewards the ones that invest more.

KEYWORDs: fiscal performance; local governments; reelection; voting behavior.

\section{Introdução}

O objetivo deste artigo é analisar a relação entre a gestão fiscal e o instituto da reeleição nas eleições para prefeitos municipais no Brasil sob múltiplas dimensões e numa perspectiva temporal abrangente. A pesquisa procura responder as seguintes questões: i) a expectativa de reeleição do prefeito influencia o gerenciamento de sua política fiscal?; e ii) os cidadãos premiam ou punem os prefeitos de acordo com o desempenho fiscal de seus governos? No primeiro caso, a hipótese se fundamenta no modelo de reputação (reputation model), enquanto o segundo dialoga com a literatura que avalia os efeitos da política fiscal sobre o comportamento do eleitorado, incluindo pressupostos da perspectiva da escolha racional na explicação do voto.

O tema é relevante por diversas razões. A análise da relação entre a gestão fiscal e a dinâmica do sistema político se apresenta como um fértil objeto de estudo comparado, principalmente, devido ao amplo processo de descentralização fiscal pós-Constituição de 1988, no qual os municípios passaram a desempenhar papel de destaque, com aumento sensível das suas responsabilidades, seja no âmbito das receitas quanto das despesas (Afonso e Araújo, 2000; Souza, 2004).

A reeleição para os cargos majoritários no Brasili é um fenômeno relativamente recente na história política brasileira, instituído somente em 1997, com a Emenda Constitucional no 16. Desde então, predomina o debate na opinião pública sobre a manutenção ou extinção da reeleição, embora, na maioria das vezes, sem fundamentação empírica suficiente.

Os contrários à reeleição defendem que o mecanismo gera mais personalismo do poder, riscos de perpetuação no cargo e estimula situações de abuso de poder. O lado oposto argumenta que um mandato é muito curto para realizar grandes projetos de governo e que a reeleição valoriza a experiência administrativa e não gera descontinuidade em políticas públicas efetivas e populares.

No Brasil, passados quatro mandatos de prefeitos após essa mudança, a literatura brasileira ainda carece de compreensão dos reais efeitos da reeleição sobre o comportamento dos gestores públicos e, por conseguinte, de suas políticas fiscais. 
Nesse sentido, este artigo aborda essa relação a partir de um recorte temporal o mais amplo possível, isto é, incluindo as quatro gestões municipais após 1997, e analisando não apenas o impacto da expectativa de reeleição sobre a gestão fiscal como também o seu inverso: os efeitos da política fiscal da prefeitura sobre a probabilidade de reeleição do mandatário. Para tanto, a pesquisa utiliza como proxy de desempenho fiscal três dimensões centrais: arrecadação própria, investimentos e gasto social. É importante ressaltar que a análise da relação entre reeleição e gestão fiscal no Brasil não é inédita; entretanto, a literatura foca os níveis de despesas e se restringe, geralmente, a apenas um mandato. Ademais, diferentemente da presente abordagem, a literatura enfatizava os partidos. Todavia, segundo o Tribunal Superior Eleitoral, quase um terço dos prefeitos que concorrem à reeleição está em legenda distinta da primeira eleição. Como a informação dessa mudança só é disponibilizada no pleito seguinte e não no momento da troca de partido, não é possível avaliar a qual partido o prefeito esteve filiado na maior parte do mandato. Consequentemente, a alternativa de se analisar o comportamento do eleitor em relação ao desempenho de um partido é prejudicada.

Além desta introdução, o artigo discute a literatura de economia política direcionada à compreensão da relação entre processo eleitoral e política fiscal. No tópico seguinte, as variáveis do modelo da primeira hipótese são apresentadas e seus resultados discutidos. A variável dependente do segundo modelo, probabilidade de reeleição entre 2000 e 2012, é analisada, o modelo discernido e as estimativas debatidas. Por fim, algumas conclusões são tecidas.

\section{Revisão de literatura}

Os estudos acerca da relação entre processo eleitoral e políticas públicas estão entre os temas mais recorrentes da literatura de economia política. Desde meados do século passado, pesquisadores vêm se dedicando a investigar os efeitos da dinâmica política sobre as decisões governamentais e vice-versa (Blomquist, 1999). Logo, prevalece certo consenso de que tais dimensões são altamente interligadas. Desde então, algumas correntes teóricas têm dominado o campo de estudo.

Uma das correntes precursoras é a de ciclos políticos (political business cycles), fundamentada no paradigma da escolha racional (Nordhaus, 1975). A premissa é que o ciclo de negócios (macroeconomia do setor público) seja influenciado pela agenda do ciclo eleitoral. O detentor de um cargo se comporta de maneira oportunista, em anos eleitorais, utilizando-se de política expansionista para estimular a economia, seja com crescimento do PIB real ou redução do desemprego, de modo a potencializar suas chances de reeleição. No início do governo, em contrapartida, a tendência é oposta, os políticos adotam políticas restritivas, aumentando o desemprego e reduzindo a inflação. Essa conduta é considerada oportunista na medida em que os governantes tomam decisões de política econômica, de forma distinta no decorrer do mandato e no período eleitoral, de modo a maximizar as chances de sua reeleição ou de seu partido. Entretanto, os estudos aplicados dessa vertente se preocupam menos com a análise da condução da política econômica e mais com a forma 
como o eleitorado avalia o ciclo, isto é, se o cidadão pune ou premia o candidato dentro de um enfoque de voto econômico.

A partir do modelo dos ciclos políticos, os estudos de Rogoff e Silbert (1988) e Rogoff (1990) argumentam que ciclos econômicos e ciclos eleitorais se combinam. Neste último, os governantes se apresentam ao eleitorado como gestores eficientes. Diferentemente da versão original, a competência é demonstrada mediante a manutenção e o aumento de alguns gastos mais perceptíveis ao público e diminuição de outros, reduzindo assim a relevância dos efeitos da política monetária.

Embora não concorde com a caracterização do eleitor como míope, a perspectiva reconhece a existência e uma relação de assimetria informacional, na qual o fenômeno cíclico ocorre porque os efeitos das decisões sobre a política fiscal, como redução tributária por exemplo, em anos eleitorais, mesmo com eventuais distorções nas contas públicas futuras, tendem a refletir em uma imagem de governante competente. Essa relação assimétrica é temporária, permanecendo, principalmente, durante os períodos de eleições.

Uma segunda perspectiva consiste no denominado modelo de reputação (reputation model). Diante de um cenário de informação imperfeita e racionalidade dos agentes políticos, a reeleição pode funcionar tanto como ferramenta do eleitorado para reprimir comportamentos oportunistas quanto como incentivo ao governante para cativar boas relações com os eleitores (Besley e Case, 1995, 2003). O modelo pressupõe a relação entre o político e os eleitores em dois momentos. O governante avalia o nível de esforço num primeiro mandato, tendo ciência de que será avaliado pelos eleitores que se beneficiam ou não da distribuição de bens públicos no primeiro momento. A utilidade do político no segundo mandato está atrelada diretamente ao seu desempenho no período anterior. Ou seja, com base na reputação que ele desenvolveu com o eleitorado na implementação das políticas públicas.

Em síntese, a popularidade do político em um segundo mandato está relacionada com uma distribuição de bens públicos perceptível e próxima dos interesses dos eleitores que o reelegeram. Em situações em que os governantes não podem se reeleger mais, sua perspectiva de utilidade tende a ser de curto prazo. O modelo foi testado por Besley e Case (1995) em pesquisa sobre o comportamento de governadores norte-americanos que identifica políticas tributárias diferentes entre os governantes em processo de reeleição (incumbents) e os que não podem se reeleger, além de detectar comportamentos distintos entre os partidos Republicano e Democrata na condução da política fiscal. Enquanto a primeira legenda tem como reputação a tendência de redução de impostos, os democratas tendem a elevar a carga tributária.

Quanto à relação entre política fiscal e desempenho dos governantes, o estudo de Peltzman (1990), com base na política norte-americana (1950 a 1988), analisa os efeitos das despesas públicas sobre a votação dos candidatos à reeleição. As estimativas sugerem que esse eleitorado adota uma postura punitiva em relação aos políticos que aumentam as despesas, sobretudo, nas proximidades do pleito. Surpreendentemente, incrementos de gastos independentemente da área de política pública geram sanções do eleitorado nas eleições presidenciais, enquanto nos governos estaduais são os incrementos das despesas 
na saúde e na educação que resultam em impactos negativos aos governantes em processo de reeleição.

No âmbito internacional, Brender e Drazen (2003), com base em uma amostra de 74 países entre 1960 e 2003, abordam como a gestão fiscal influencia as chances de reeleição dos chefes do Poder Executivo. Analisando a probabilidade de reeleição, tanto dos governantes como dos seus partidos, a partir de dados de déficit público e do crescimento do PIB em ano eleitoral e nos demais anos da gestão, os autores demonstram que, especialmente em nações desenvolvidas, as urnas premiam aqueles que apresentam desempenho fiscal mais conservador, isto é, promovem reduções na relação déficit público sobre o PIB.

No Brasil, os estudos testam esses modelos e teorias desde a última década, quando os Executivos passaram a usufruir do direito a uma reeleição. Em uma dessas pesquisas, Meneguin e Bugarin (2005) aprimoram os modelos estatísticos testados anteriormente (Meneguin e Bugarin, 2001) e analisam as influências das expectativas de reeleição sobre as despesas, em ano eleitoral, e também o impacto das variáveis políticas, econômicas e fiscais sobre a probabilidade de reeleição, nas eleições municipais de 2000. As evidências empíricas sugerem que os candidatos à reeleição gastam menos em ano eleitoral. Quanto mais aumenta a renda per capita, menores as chances de reeleição, e diante da expectativa de reeleição, em ano eleitoral, as despesas per capita são menores. Quanto à segunda análise, os autores afirmam que a probabilidade do prefeito aumenta na medida em que os gastos de custeio se reduzem e os de investimentos se elevam. Isto é, o eleitorado premia os governantes que focam mais as obras públicas e menos a manutenção da máquina administrativa. Em boa medida, convergem com os achados de Peltzman (1990) no que tange à tendência de premiação dos políticos que adotam uma gestão mais restritiva. Da mesma forma, o eleitor beneficia os prefeitos que conseguem mais recursos para o município, principalmente, aqueles oriundos de transferências intergovernamentais. Outro resultado interessante é o fato de que o alinhamento partidário entre o prefeito e o presidente da República tende a beneficiar a reeleição municipal.

Com enfoque nos governos estaduais, Libânio (2003) aborda a reeleição dos partidos para o cargo de governador, de 1982 a 1998, com ênfase nos impactos de indicadores socioeconômicos. As estimativas indicam que as melhorias sociais e econômicas refletem em boa avaliação da gestão nas urnas, logo, permanência do partido no cargo.

Nakaguma (2006) testa a relação entre comportamento das receitas e das despesas sobre as chances de reeleição dos governadores no Brasil. A partir do modelo de ciclos políticos, o autor demonstra que distorções oportunistas, em períodos eleitorais, tanto na receita como na despesa, impactam de forma positiva a proporção de votos obtidos nas eleições. Todavia, a pesquisa indica um declínio dessa influência no decorrer do tempo, reduzindo a capacidade de utilização da política fiscal para fins eleitoreiros. Diferente de Meneguin e Bugarin (2005), o alinhamento partidário, nesse caso entre governador e presidente, reflete negativamente nos votos do primeiro. Também contrário aos estudos anteriores, Nakaguma e Bender (2006), ao incluírem o impacto da Lei de Responsabilidade Fiscal (LRF) nos modelos, detectam que a influência dos ciclos políticos é ainda mais acentuda nas eleições para governador. 
Voltando às abordagens municipais, Araujo Junior, Shikida e Silva (2003) afirmam que, na maioria das prefeituras de Minas Gerais, a probabilidade de reeleição em 2000 aumenta em cenários fiscais nos quais as despesas são menores e as receitas maiores, sinalizando que a reeleição funciona como mecanismo de controle dos gastos. Os resultados também indicam significância estatística das variáveis de alinhamento do prefeito tanto com o governador quanto com o presidente da República. Contudo, em análise dos efeitos das transferências voluntárias sobre a reeleição municipal no estado de Bahia entre 1997 a 2004, Carrera-Fernandez e Pereira (2007) rechaçam os efeitos desses alinhamentos para reeleição de prefeitos também nas eleições de 2000 e 2004.

Utilizando o modelo de seleção de Heckman na abordagem de todos os municípios brasileiros, Mendes e Rocha (2004) e Mendes (2004) incorporam uma variável dicotômica para mensurar a influência do fato de o município ser novo sobre as chances de reeleição no pleito de 2000. As estimativas sugerem que a probabilidade de recondução ao cargo do prefeito se eleva em cidades criadas entre 1993 e1996, o que pode estar relacionado com o fato de esses municípios, majoritariamente, não possuírem dívidas. Os autores também confirmam o impacto positivo, tanto do alinhamento com o presidente quanto do desempenho do prefeito na eleição anterior (1996) sobre a reeleição.

Mais recentemente, Novaes e Mattos (2010) aplicam o modelo de reputação para mensurar o impacto aos gastos na saúde sobre a reeleição nas eleições municipais de 2000 e 2004. Evidências confirmam a premissa do modelo ao demonstrarem que onde os prefeitos tentam um novo mandato, esses gastos são maiores. Enquanto os prefeitos em um segundo mandato não se esforçam da mesma forma na destinação de recursos para a saúde pública.

Em suma, a revisão de literatura retrata a sofisticação e complexidade dos estudos comparativos nacionais nas investigações acerca da relação entre política fiscal e eleições. Cabe ressaltar, todavia, que, passados quatro mandatos após instituição da reeleição para cargos majoritários no Brasil, a literatura ainda carece de análise de todo esse período e não apenas de uma ou duas eleições. Outro aspecto relevante envolve a preocupação dominante em analisar um único exercício financeiro e não a política fiscal do mandato como um todo. Por fim, a ênfase da maioria dos trabalhos recorre sobre as dimensões de nível de gasto per capita e endividamento, reduzindo a importância de outros aspectos centrais na condução da política fiscal, como arrecadação própria, investimentos e gasto social.

É, justamente, para ocupar essas lacunas que o presente artigo se propõe a analisar a relação entre essas variáveis e a reeleição de forma abrangente. Isso se dá com foco na totalidade dos municípios brasileiros, nos quatro pleitos (1996 a 2000) e também com ênfase na gestão fiscal de todo o mandato e não apenas de exercícios financeiros isolados. ${ }^{2}$

\footnotetext{
${ }^{2}$ As bases de dados desta pesquisa estão disponíveis, sob demanda, para fins de pesquisas futuras sobre o tema.
} 


\section{A reeleição influencia a gestão fiscal?}

Este tópico é dedicado a testar a primeira hipótese desta pesquisa: o prefeito em primeiro mandato tende a apresentar uma melhor gestão fiscal devido à expectativa de se reeleger.

O principal embasamento teórico advém do modelo de reputação (reputation model) que preconiza a importância da relação de credibilidade entre o governante e os eleitores (Besley e Case, 1995). Quando o primeiro tem uma expectativa de se manter no cargo por mais um mandato, prevalece a percepção de que ele possui incentivos para agradar a maioria do eleitorado de modo a facilitar a consecução desse objetivo: reeleger-se. Por outro lado, o mesmo comportamento não se observaria em prefeitos de segundo mandato, haja vista que a limitação de apenas uma reeleição tenderia a diminuir sua motivação em apresentar uma melhor gestão fiscal.

A gestão fiscal, portanto, constitui a variável dependente do modelo estatístico. Nesta pesquisa, conforme já discutido anteriormente, a qualidade da política fiscal no município é retratada por três variáveis: arrecadação própria, investimentos e gasto social. Todas elaboradas com base nos dados disponíveis no Finbra/STN ${ }^{3}$ e com recorte temporal de 2000 a 2012, ou seja, a partir do período em que os municípios brasileiros eram governados por prefeitos de primeiro e segundo mandato.

A arrecadação própria é medida pela média do percentual das receitas correntes da prefeitura oriundas de tributos municipais em cada mandato do prefeito. $\mathrm{O}$ indicador demonstra a capacidade do governo local em exercer seu poder tributário de modo a gerar mais recursos para a implementação e gestão das políticas públicas e, por conseguinte, gerar menos dependência em relação às transferências intergovernamentais.

Cabe ressaltar que, além dos fatores de renda e porte populacional dos municípios que possuem reconhecida influência sobre o desempenho fiscal local, as prefeituras muitas vezes adotam o comportamento denominado de "preguiça" ou "negligência" tributária. Em outros termos, prefeituras que mesmo com alto potencial de arrecadação possuem baixa coleta de impostos de sua competência (Arretche et al., 2007), o que reforça a importância da análise para essa dimensão do ponto de vista da qualidade da política fiscal.

Sua fórmula de construção é a seguinte:

$$
\sum \text { Arrecadação Própria }=\frac{\text { Receita Tributária Municipal }}{\text { Receita Corrente }}
$$

É consensual na literatura econômica que um dos pressupostos do desenvolvimento se fundamenta na capacidade de os governos fomentarem e, principalmente, promoverem o investimento (Ferreira, 1996). Muito embora a taxa de investimento governamental seja

\footnotetext{
${ }^{3}$ O Relatório Finbra da Secretaria do Tesouro Nacional que reporta as informações contábeis anualmente apresentadas pelas prefeituras em atendimento à Lei no 4.320, de 17 de março de 1964, e do artigo 51 da LRF.
} 
relativamente baixa em relação a comparações internacionais (Afonso e Junqueira, 2009), seu papel continua central para prover o crescimento econômico e a qualidade de vida da população. No nível municipal, tais despesas normalmente são destinadas à construção de hospitais e escolas, saneamento básico, pavimentação, entre outras. Nesse caso, as vinculações de despesas constitucionais e os limites da LRF acabam por tornar esse tipo de gasto como um dos que mais refletem a discricionariedade e a qualidade da gestão fiscal da prefeitura, haja vista que a parcela destinada para investimentos demanda do prefeito a capacidade de cumprir as regras supracitadas de maneira mais eficaz, de modo a gerar excedentes no orçamento para se investir.

Logo, o indicador Investimentos demonstra a capacidade do governo local em exercer seu poder tributário de modo a gerar mais recursos para a implementação e gestão das políticas públicas e, por conseguinte, gerar menos dependência em relação às transferências intergovernamentais. Os utilizados dados se referem à execução e não à dotação orçamentária, o que possibilita captar com maior precisão a qualidade das despesas da prefeitura durante o período financeiro. ${ }^{4} \mathrm{~A}$ medida é composta pela média dos recursos municipais destinados a investimentos sobre as receitas correntes em cada mandato, conforme fórmula a seguir:

$$
\sum \text { Investimentos }=\frac{\text { Investimentos }}{\text { Receita Corrente }}
$$

A variável gastos sociais inclui a média do somatório das seguintes funções orçamentárias: assistência social, cultura, educação, habitação, previdência, saúde, saneamento e urbanismo sobre as receitas correntes em cada mandato. Assim como na variável de investimentos, os dados são da execução e não da dotação orçamentária. Infelizmente, não é possível restringir as análises somente às despesas dos recursos próprios municipais, pois os dados disponíveis não distinguem entre o que é efetivamente verba municipal e dos demais entes federados - estados e União. Isso não impede, todavia, a abordagem da priorização da alocação dos recursos na área social, uma vez que as prefeituras possuem relativo grau de discricionariedade na gestão orçamentária. Portanto, a variável de gastos sociais pode ser caracterizada como indicativo de comprometimento da prefeitura com a área social em detrimento das demais funções governamentais. A fórmula é a seguinte:

$$
\sum \text { Gastos sociais }=\frac{\text { Somatório dos Gastos Sociais }}{\text { Receita Corrente }}
$$

Do outro lado do modelo, a principal variável independente ou explicativa é o fato de o prefeito estar em primeiro mandato ou não, representada pela variável dicotômica Reeleito:

\footnotetext{
${ }^{4}$ Essa opção é a mais adequada em função do caráter autorizativo do orçamento público no Brasil, isto é, o Poder Executivo em suas três esferas de governo não é obrigado a executar as despesas estabelecidas na Lei Orçamentária Anual (LOA). Logo, a dotação orçamentária presente na LOA na maioria das vezes não reflete o padrão de gastos de fato executado.
} 
0 para prefeito em primeiro mandato e 1 para prefeito em segundo mandato, que no caso brasileiro não pode mais concorrer ao mesmo cargo. Conforme já discutido, a expectativa é que se observem variações na qualidade da gestão fiscal em governos de prefeitos recém-empossados, ou seja, mais arrecadação própria, mais investimentos e mais gastos na área social.

Ainda na esfera política, a segunda variável do modelo multivariado para explicar a qualidade da gestão fiscal é a força eleitoral do prefeito, retratada pela Margem de Vitória em relação ao segundo colocado na última eleição. A variável demonstra o grau de dificuldade com que o prefeito alcançou o cargo ou se manteve (no caso de segundo mandato) no poder. Espera-se que, quanto maior essa diferença, menor seja a preocupação com a política fiscal, supondo que o governante possua certo patrimônio eleitoral já conquistado.

O alinhamento partidário entre dirigentes de diferentes esferas de governo é utilizado pela literatura como um fator que pode influenciar a condução da política pública. Nesse sentido, o modelo incorpora as variáveis: alinhamento do partido do prefeito e a Base do Presidente da República ${ }^{5}$ (Base) e alinhamento entre o partido do prefeito e o partido do governador (Governador). Elas são categorizadas nos casos de períodos de dois anos e quatro anos de alinhamento, considerando que as eleições para esses cargos ocorrem em períodos distintos.

Os dados dessas variáveis de ordem política são oriundos do Tribunal Superior Eleitoral (TSE); entretanto, cabe ressaltar que se referem aos prefeitos eleitos nas eleições regulares (2000-04-08), haja vista que não está disponível informação sistematizada pela justiça eleitoral para os casos de renúncia, afastamento, falecimento, entre outros.

Por fim, alguns aspectos de caráter socioeconômico e demográficos também podem influenciar a gestão fiscal e, portanto, são inseridos como variáveis de controle no modelo Taxa de urbanização (2000-07-10), população (2001-05-09), bem como a PIB per capita municipal (2000-04-08). Todas essas variáveis são oriundas do Instituto Brasileiro de Geografia e Estatística (IBGE).

Assim, o modelo possui o seguinte formato, onde $\mathrm{i}=5557, \mathrm{t}=2001-04 ; 2005-08$; 2009-12:

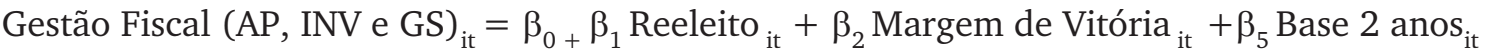

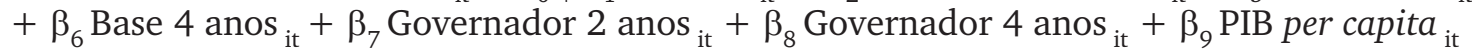
$+\beta_{10}$ População $_{\text {it }}+\beta_{8}$ Urbanização $_{\text {it }+} \mathrm{u}_{\text {it }}$

O universo desta investigação compreende quase a totalidade dos municípios brasileiros; entretanto, as variáveis dependentes apresentaram alguns (poucos) casos faltosos (missings), uma vez que o quantitativo de declarações financeiras dos municípios no relatório Finbra/STN não é uniforme durante os períodos analisados. Logo, para não perder toda a informação do município, foram realizadas inputações desses dados com a média de cada variável usando a média dos mandatos dentro do município em questão. Em função da falta

\footnotetext{
${ }^{5}$ Considera-se Base do Presidente de República a relação de partidos políticos que possuem ao menos um ministro de Estado no ínicio do mandato presidencial.
} 
de simetria (assimetria) e do peso das caudas da distribuição (curtose) em algumas variáveis, foi necessário realizar transformações, detalhadas no apêndice do artigo.

Os resultados dos modelos longitudinais de efeito fixo no tempo (mandato) com corte transversal em municipios, expostos na tabela 1, demonstram que os modelos, apesar de possuírem coeficientes de determinação distintos, trazem estimativas interessantes à análise. Antes, é importante ressaltar que, devido à grande amostra, os testes F são válidos assintoticamente, entretanto, algumas variáveis não apresentam significância estatística, enquanto de acordo com a estatística F as significâncias globais das regressões se confirmam. ${ }^{6}$

Tabela 1

Efeitos sobre a gestão fiscal (2000-12)

\begin{tabular}{|c|c|c|c|}
\hline & $\begin{array}{c}\text { Arrecadação Própria } \\
\text { Modelo } 1\end{array}$ & $\begin{array}{c}\text { Investimentos } \\
\text { Modelo } 2\end{array}$ & $\begin{array}{c}\text { Gasto Social } \\
\text { Modelo } 3\end{array}$ \\
\hline Reeleito & $\begin{array}{r}-0,000 \\
(0,000) \\
\end{array}$ & $\begin{array}{c}0,006 * * * \\
(0,001)\end{array}$ & $\begin{array}{c}0,004^{* * *} \\
(0,001)\end{array}$ \\
\hline Margem de Vitória & $\begin{array}{c}0,000 \\
(0,000)\end{array}$ & $\begin{array}{c}0,004 * * * \\
(0,000)\end{array}$ & $\begin{array}{c}0,004 * * * \\
(0,000)\end{array}$ \\
\hline Base 2 anos & $\begin{array}{c}-0,001^{* * *} \\
(0,000)\end{array}$ & $\begin{array}{l}0,003^{* *} \\
(0,001)\end{array}$ & $\begin{array}{l}-0,000 \\
(0,000) \\
\end{array}$ \\
\hline Base 4 anos & $\begin{array}{l}-0,000 \\
(0,000)\end{array}$ & $\begin{array}{c}0,002 * * * \\
(0,001)\end{array}$ & $\begin{array}{c}-0,001^{* * *} \\
(0,002)\end{array}$ \\
\hline Governador 2 anos & $\begin{array}{l}0,001^{* * *} \\
(0,000)\end{array}$ & $\begin{array}{c}0,000 \\
(0,001)\end{array}$ & $\begin{array}{c}-0,015^{* * *} \\
(0,001)\end{array}$ \\
\hline Governador 4 anos & $\begin{array}{l}-0,000 \\
(0,000)\end{array}$ & $\begin{array}{c}0,004 \\
(0,001)\end{array}$ & $\begin{array}{c}0,010^{*} \\
(0,002) \\
\end{array}$ \\
\hline Urbanização & $\begin{array}{c}0,030 * * * \\
(0,001)\end{array}$ & $\begin{array}{c}-0,030 * * * \\
(0,002)\end{array}$ & $\begin{array}{c}0,050 * * * \\
(0,004)\end{array}$ \\
\hline PIB per capita & $\begin{array}{l}0,020^{* * *} \\
(0,000)\end{array}$ & $\begin{array}{c}0,007 * * * \\
(0,000)\end{array}$ & $\begin{array}{c}-0,064 * * * \\
(0,001)\end{array}$ \\
\hline População & $\begin{array}{l}0,011^{* * *} \\
(0,000)\end{array}$ & $\begin{array}{l}-0,001^{* *} \\
(0,000)\end{array}$ & $\begin{array}{c}0,030 * * * \\
(0,001)\end{array}$ \\
\hline Constante & $\begin{array}{c}-0,250 * * * \\
(0,004)\end{array}$ & $\begin{array}{c}0,065^{* * *} \\
(0,000)\end{array}$ & $\begin{array}{c}0,956^{* * *} \\
(0,060)\end{array}$ \\
\hline $\begin{array}{c}\mathrm{R} 2 \\
\mathrm{~N}\end{array}$ & $\begin{array}{c}0,54 \\
16671\end{array}$ & $\begin{array}{c}0,04 \\
16671\end{array}$ & $\begin{array}{c}0,37 \\
16671\end{array}$ \\
\hline Estatística F & $164.53^{* * *}$ & $206.77^{* * *}$ & $26,69 * * *$ \\
\hline
\end{tabular}

Notas: Coeficientes estimados e erros-padrões entre parêntesis.

Significância estatística: * significa valor-P $<0,1$; ** valor-P $<0,05$; *** valor-P $<0,01$.

Fonte: Elaboração própria.

\footnotetext{
${ }^{6}$ Foram realizados testes que demonstraram não haver problemas de colinearidade, endogeneidade e heterocedasticidade.
} 
O modelo 1 explica 54\% da variação na arrecadação própria do município; entretanto, o coeficiente da principal variável independente, reeleito, não é estatisticamente significativo. Em outras palavras, o desempenho da gestão fiscal entre os prefeitos de primeiro ou de segundo mandato não se diferencia no que tange à arrecadação de tributos municipais.

Em relação às demais variáveis políticas, as evidências empíricas são semelhantes. Apesar de algumas apresentarem significância estatística, os coeficientes não possibilitam confirmar impactos substantivos das variáveis margem de vitória e as de alinhamento partidário sobre os resultados dos prefeitos em termos de coleta de impostos durante o mandato. Em relação às variáveis de controle, conforme esperado, quanto mais urbanizado, populoso e rico o município, maiores tendem a ser as arrecadações das prefeituras.

No que tange aos investimentos, o modelo tem baixa capacidade explicativa de modo geral, com $\mathrm{R}^{2}$ bem baixo. O fator reeleição tem efeitos sobre a gestão fiscal, todavia, no sentido contrário ao teoricamente previsto. Mesmo com um impacto pequeno, essa estimativa no modelo 2 sugere que o fato de o prefeito não ter direito a um novo mandato reflete em incremento de $0,6 \%$ na parcela destinada a investimentos, mantendo os demais fatores constantes. Resultado parecido à variável margem de vitória do prefeito, cujo coeficiente positivo se contrapõe à expectativa, isto é, a folga em relação ao segundo colocado na eleição anterior não indica redução nos investimentos.

Ser de partido da base do presidente importa nessa dimensão da política fiscal municipal. Embora com efeitos reduzidos, as afinidades político-partidárias com o governo federal ampliam a parcela destinada a investimentos. Por outro lado, o alinhamento com o governador não apresenta efeitos estatisticamente significativos.

As evidências empíricas do modelo 2 também demonstram que os investimentos municipais tendem a ser menores proporcionalmente em municipalidades mais urbanas e populosas; por outro lado, crescem de acordo com a riqueza da cidade.

No modelo 3, o coeficiente de determinação $\left(\mathrm{R}^{2}\right)$ explica quase $40 \%$ dos gastos sociais. Assim como o anterior, o coeficiente estimado da variável reeleito mesmo estatisticamente significativo não possibilita afirmarmos que a expectativa de um novo mandato tenha algum efeito substantivo sobre a priorização do prefeito nas despesas do campo social. Sobretudo, quando comparado à média dos gastos sociais que gira em torno de $65 \%$ dos recursos municipais. O resultado diverge do detectado por Novaes e Mattos (2010) com a ênfase na relação entre os gastos da saúde e as eleições de 2000 e 2004.

Ainda na dimensão política, novamente, a estimativa de margem de vitória refuta a relação esperada, com um coeficiente próximo do identificado no modelo 2 . O alinhamento partidário, porém, tem na prática poucos efeitos sobre os dispêndios municipais em política social. Isso reforça a visão de uma tendência crescente de maior vinculação das transferências intergovernamentais nesse setor, o que, em boa medida, reduz a discricionariedade do gestor local em gerenciar esses recursos.

Quanto às variáveis de controle, a urbanização e a população apresentam relação direta aos gastos sociais da prefeitura, ou seja, quanto mais urbanizado e populoso, maior a 
parcela destinada à política social pela prefeitura. Surpreendentemetne, a variável PIB per capita influencia negativamente os gastos sociais.

Em síntese, as estimativas dos modelos não propiciam condições empíricas para que se verifiquem desempenhos fiscais distintos entre os governantes, com ou sem a expectativa de reeleição, o que não possibilita confirmar a principal premissa do modelo de reputação. Por conseguinte, ao analisar a gestão fiscal dos municípios brasileiros, mais especificamente arrecadação própria, investimentos e gastos sociais durante três mandatos, o artigo refuta a hipótese de que o prefeito em primeiro mandato tende a apresentar melhor desempenho devido à expectativa de se reeleger.

\section{A gestão fiscal influencia a reeleição?}

Neste tópico, a análise se direciona para testar a segunda hipótese da pesquisa: o prefeito que apresenta uma melhor gestão fiscal tende a ser premiado pelo eleitorado com a sua reeleição. A variável política se torna função da gestão fiscal.

Teoricamente, a hipótese dialoga com a literatura que avalia os efeitos da política fiscal sobre o comportamento do eleitorado (Rogoff e Silbert, 1988; Rogoff, 1990; Peltzman,1990; Brender e Drazen, 2003). Além disso, é possível também traçar uma avaliação sobre a conduta dos eleitores brasileiros, passadas quatro eleições democráticas após a aprovação do instituto da reeleição. Ao focar a investigação dos efeitos dos resultados da gestão fiscal sobre as chances de reeleição do prefeito, o trabalho possibilita analisar se os cidadãos premiam ou punem políticos de acordo com o desempenho de seu governo e, por conseguinte, geram incentivos positivos para decisões de políticas públicas voltadas para a boa gestão.

Segundo o pressuposto de racionalidade, o eleitor remete ao caráter instrumental do voto - capacidade do eleitor em reconhecer seus interesses e votar naqueles que melhor convergem com seus objetivos e crenças. Em suma, prevalece uma tendência a votar com base nos efeitos da economia no bolso dos cidadãos. Dentro dessa lógica, as eleições possuem como função central propiciar aos cidadãos um momento para realizarem a avaliação dos governantes (Powell, 2000; Manin, Przeworski e Stokes, 1999). Logo, processo eleitoral é o principal mecanismo da accountability que pode ser utilizado pelos eleitores para punir os atuais ocupantes dos cargos, visão-padrão do voto retrospectivo (Fiorina, 1981; Key Jr., 1966). Mesmo desinformados, os cidadãos possuem um pouco de dados que possibilitam interpretar o desempenho do governo. Quanto menos eles sabem sobre os detalhes de políticas públicas vigentes, mais eles tendem a se basear no voto retrospectivo como atalho para tomar decisões eleitorais.

Portanto, a variável dependente desta pesquisa - probabilidade de o prefeito ser reeleito - é considerada exógena ao modelo e possui o valor de 0 , na situação de o atual prefeito perder a eleição, ou 1 quando o atual prefeito vence o pleito.

A probabilidade média de reeleição nas eleições para prefeito no Brasil é de $60 \%$. Em média, de cada 10 candidatos à reeleição, seis foram bem-sucedidos. Essa performance é 
bastante heterogênea quando analisamos os resultados por eleição e quando se segregam os municípios por região e porte populacional. A figura 1 retrata essa diversidade e, de modo geral, não é possível identificar nenhum padrão claro no decorrer dessas eleições.

\section{Figura 1}

Probabilidade Média de Reeleição, por região e porte populacional (2000-12)

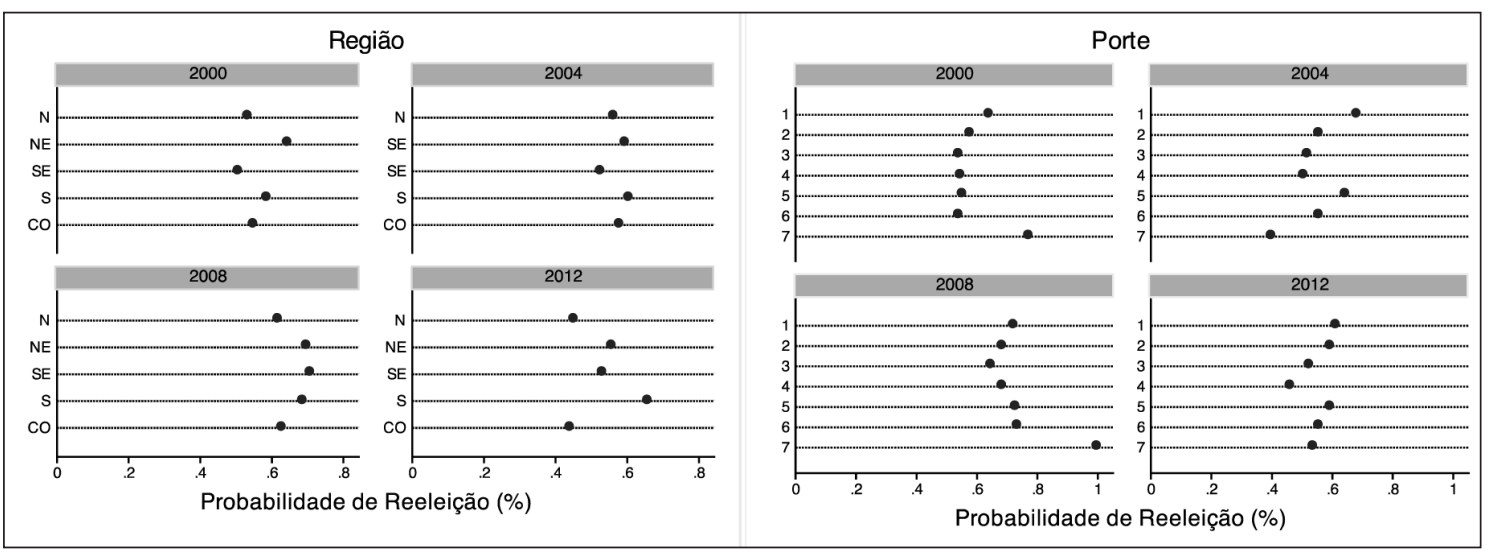

Fonte: TSE; elaboração própria.

Para explicar os determinantes da reeleição nos municípios brasileiros, as principais variáveis independentes envolvem as variáveis que representam a gestão fiscal, ou seja, a média de \% de arrecadação própria, de investimentos e gasto social em relação com as receitas correntes no decorrer de cada um dos quatro mandatos analisados (1997-2000; 2001-04; 2005-08; 2009-12). Com essas variáveis é possível mensurar se os prefeitos com melhor desempenho na gestão fiscal tendem a ser reeleitos.

O modelo multivariado incorpora ainda outros fatores, especialmente, da dimensão política, como também controles de caráter socioeconômico e demográfico numa base de mais de 10 mil observações.

Na esfera política, a primeira variável para explicar a reeleição é a força eleitoral do prefeito, calculada pela margem de vitória em relação ao segundo colocado na eleição anterior quando foi eleito, e visa mensurar os efeitos de uma suposta base prévia do candidato. ${ }^{7}$ Trata-se de uma proxy da fidelidade do eleitorado ao candidato dentro da suposição de que existem eleitores fiéis, independentemente do desempenho do prefeito, e que constituem um estoque no momento de partida da campanha (Peltzman, 1990). Para testar o impacto do alinhamento partidário com outras esferas de governo sobre as chances de reeleição, o modelo incorpora ainda as variáveis de alinhamento do partido do prefeito e a Base do Presidente da República (Base) e o alinhamento entre o partido do prefeito e o partido do governador

\footnotetext{
${ }^{7}$ A margem de vitória é mensurada nas eleições de 1996 a 2008.
} 
(Governador). Elas também são categorizadas nos casos de períodos de dois anos e quatro anos de alinhamento. Devido à relevância desses cargos na condução de importantes políticas públicas como políticas econômicas e grandes obras, espera-se que a proximidade com o partido do governador e do presidente aumente a probabilidade de reeleição do prefeito.

De forma a controlar a dependência intraindivíduos, são incluídos três dummies para os mandatos de 2001-04, 2005-08 e 2009-12, seguindo o exemplo de Landerman, Mustillo e Land (2011). Acredita-se ainda que fatores estruturais das municipalidades também podem impactar as chances de reeleição e, por conseguinte, o comportamento dos eleitores. Nesse sentido, são controlados os efeitos da taxa de urbanização, população, bem como o PIB per capita municipal.

Dessa forma, o modelo apresenta o seguinte formato: ${ }^{8}$

Reeleição $_{\text {it }}=\beta_{0}+\beta_{1} \mathrm{AP}_{\text {it }}+\beta_{2} \mathrm{INV}_{\text {it }}+\beta_{3} \mathrm{GS}_{\text {it }}+\beta_{4}$ Margem de Vitória $_{\text {it }}+\beta_{5}$ Base 2 anos $_{\text {it }}$

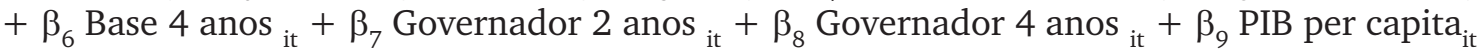
$+\beta_{10}$ População $_{\text {it }}+\beta_{11}$ Urbanização $_{\text {it }}+\mathrm{u}_{\text {it }}$

Onde,

Reeleição — variável dummy (1 se prefeito é reeleito e 0 o oposto); $\mathrm{AP}=\%$ de arrecadação própria médio durante o mandato (1997-2000; 2001-04; 2005-08;

2009-12);

INV $=\%$ de investimentos médio durante o mandato (1997-2000; 2001-04; 2005-08;

2009-12);

GS $=\%$ de gasto social médio durante o mandanto (1997-2000; 2001-04; 2005-08;

2009-12).

Margem de Vitória - margem de vitória na eleição anterior;

Base 2 - dummy para dois anos de alinhamento entre o partido do prefeito e a Base do Presidente da República;

Base 4 - dummy para quatro anos de alinhamento entre o partido do prefeito e a Base do Presidente da República;

Governador 2 - dummy para dois anos de alinhamento entre partido do prefeito e o partido do governador;

Mandatos 2001-04; 2005-08; 2009-12 — dummies para cada mandato em relação ao 1997-2000.

Governador 4 - dummy para quatro anos de alinhamento entre partido do prefeito e o partido do governador;

\footnotetext{
${ }^{8}$ É importante salientar que a inexistência de indicadores sistematizados em nível municipal de diferentes dimensões para a totalidade das cidades reduz a capacidade explicativa do modelo. A título de ilustração, os recursos da campanha eleitoral para prefeito, sem dúvida, constituem um fator crucial para a compreensão do sucesso dos candidatos. Todavia, esses dados não são disponíveis para todos os municípios antes das eleições de 2004.
} 
PIB per capita - PIB per capita do município no ano da eleição anterior; População - Estimativa da população municipal;

Urbanização — Percentual da população residente em zona urbana.

Assim como nos modelos anteriores, testes não identificaram problemas de colinearidade, endogeneidade e heterocedasticidade, como também foi preciso transformar as variáveis contínuas do modelo, exceto urbanização, devido à falta de simetria (assimetria) e ao peso das caudas da distribuição (curtose) dessas variáveis. As estatísticas descritivas encontram-se detalhadas no apêndice do artigo.

Como a variável a ser explicada é dicotômica, calculou-se a regressão logística por meio do modelo misto generalizado linear (GLMM). Os resultados, expostos na tabela 2, trazem duas formas de interpretação do modelo logit: pelos coeficientes estimados e pelo Odds Ratio.

Tabela 2

Determinantes da reeleição municipal (2000-12)

\begin{tabular}{|ccccc|}
\hline & Coeficiente & Erro-Padrão & Odds Ratio & Valor $\mathrm{P}$ \\
\hline Arrecadação Própria & $-0,067$ & 0,031 & 0,936 & 0,029 \\
Investimentos & 0,562 & 0,042 & 1,755 & 0,000 \\
Gastos Sociais & $-0,062$ & 0,153 & 0,940 & 0,687 \\
Margem de Vitória & 0,240 & 0,017 & 1,271 & 0,000 \\
Base 2 anos & $-0,110$ & 0,077 & 0,896 & 0,152 \\
Base 4 anos & $-0,016$ & 0,051 & 0,984 & 0,754 \\
Governador 2 anos & 0,096 & 0,054 & 1,101 & 0,075 \\
Governador 4 anos & 0,148 & 0,065 & 1,160 & 0,023 \\
Mandato 2001/2004 & 0,200 & 0,079 & 1,222 & 0,115 \\
Mandato 2005/2008 & 0,733 & 0,064 & 2,080 & 0,000 \\
Mandato 2009/2012 & 0,080 & 0,067 & 1,083 & 0,232 \\
População & $-0,041$ & 0,023 & 0,960 & 0,075 \\
PIB per capita & 0,013 & 0,035 & 1,013 & 0,721 \\
Urbanização & 0,039 & 0,113 & 1,040 & 0,730 \\
Intercepto & 2,043 & 0,446 & & 0,000 \\
Púmero de Observações & & & 10528 & \\
\hline Pseudo R2 & & & 0,04 & \\
\hline
\end{tabular}

Fonte: Elaboração própria.

A primeira constatação é que a arrecadação própria impacta a probabilidade de reeleição do prefeito. Não obstante, o efeito é inverso, isto é, quanto mais arrecada, menores são as chances de o prefeito ser reeleito. Em termos objetivos, o odds ratio dessa variável (0.936) indica um decréscimo na chance de reeleição na ordem de 6,4\% (1-0.936=0.064 ou 6,4\%). Esse resultado reforça o senso comum de aversão da população à cobrança de 
impostos que, no caso da política em nível local no Brasil, tende a penalizar os prefeitos que arrecadam mais.

A priorização da política social por parte dos prefeitos não confirma o esperado. Enquanto a expectativa era de que a destinação crescente das despesas nas funções sociais impactaria positivamente a reeleição, entretanto, o coeficiente da variável gasto social não apresentou efeito significativo. Em outras palavras, o resultado indica que a variação nos dispêndios das políticas sociais durante o mandato não afetou a probabilidade de o prefeito reeleger-se.

Por outro lado, os investimentos apresentam os efeitos mais expressivos sobre a probabilidade de sucesso na reeleição. Para ilustrar esse impacto, o gráfico 1 projeta as relações estimadas entre a probabilidade de reeleição do prefeito e o percentual de investimentos com as outras variáveis explicativas dos modelos fixas. Objetivamente, o maior peso na reeleição está no investimento $(\mathrm{OR}=1.755)$; isso indica $75,5 \%$ mais chance de reeleição considerando o investimento como ponto principal.

Gráfico 1

Relação entre probabilidade de reeleição e o \% de investimentos

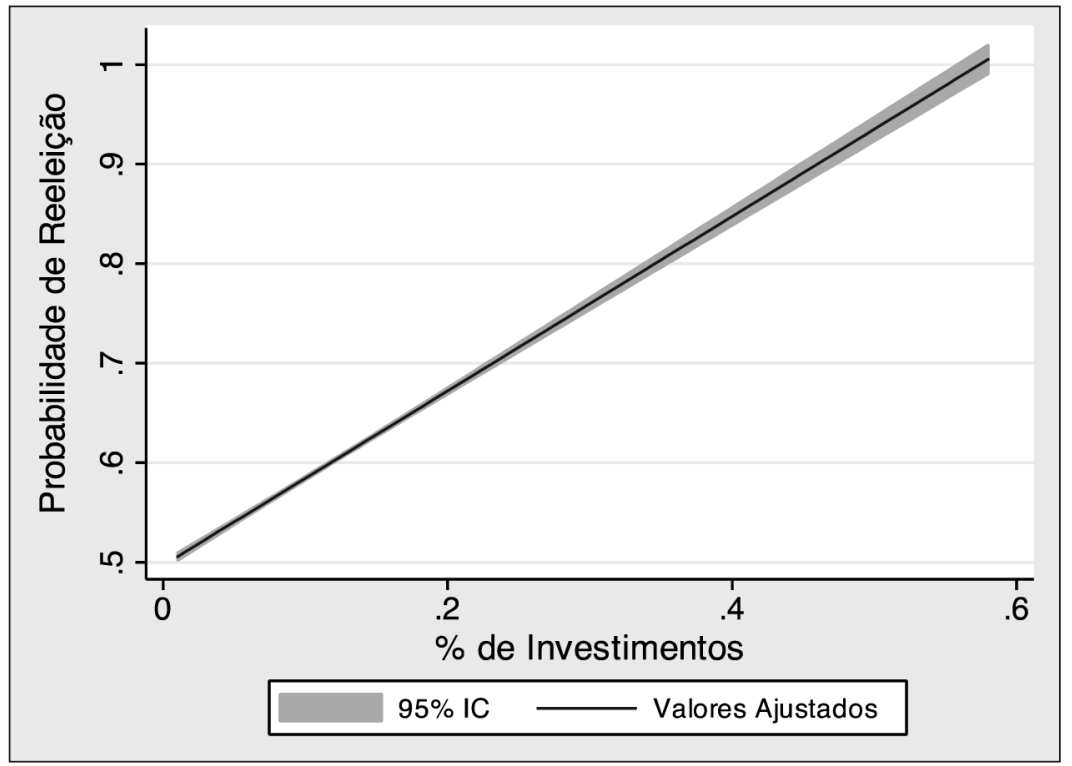

Fonte: Elaboração própria.

Sem dúvida, tal efeito não é desprezível, demonstrando que os esforços dos prefeitos na construção de hospitais e escolas, saneamento básico, pavimentação, entre outras obras, têm sido recompensados no momento da avaliação dos eleitores no período recente da democracia brasileira, convergindo com os achados de Meneguin e Bugarin (2005) nas eleições de 2000 . 
Em resumo, as evidências empíricas desse modelo corroboram para a afirmação de que o desempenho fiscal dos prefeitos importa nas tentativas de reeleição. Nos casos analisados, é possível confirmar a hipótese de que o eleitor brasileiro premia políticos com bons desempenhos, reelegendo-os, quando se analisam os efeitos dos investimentos, mas não da receita. Nesse sentido, os resultados sugerem que o cidadão oferece incentivos positivos para que os políticos locais tomem decisões de política fiscal voltadas para a valorização dos investimentos e sanções para os que mais arrecadam impostos.

Quanto à esfera política, as variáveis mostram efeitos distintos. A margem do prefeito na eleição anterior, que pode ser considerado como proxy do seu "patrimônio político", é um fator que possui um impacto estatisticamente significativo e positivo na reeleição. $\mathrm{O}$ resultado é consoante com os achados de Peltzman (1990), no caso norte-americano, e Mendes e Rocha (2004) em análise das eleições municipais no Brasil em 2000.

No tocante ao alinhamento partidário, o fato de ser do mesmo partido do governador exerce influência na possibilidade de manutenção do cargo de prefeito, enquanto o coeficiente da variável relativa ao alinhamento com a Base do Presidente da República não apresenta significância estatística.

Os odds ratios estimados indicam que ser do mesmo partido do governador por dois anos aumenta em $10 \%$ as chances do prefeito de se reeleger, enquanto por quatro anos essa probabilidade se eleva a 16\%. Em outras palavras, os resultados das últimas quatro eleições em nível municipal demonstram que a relação entre a política local e estadual possui uma dinâmica própria e importante do ponto de vista do processo eleitoral. Enquanto a relação entre governo federal e municipal não parece ser relevante. As evidências contrapõem os resultados de pesquisas anteriores, tanto com foco apenas em uma eleição (Mendes e Rocha, 2004) quanto aplicado aos municípios de Minas Gerais (Araujo Junior, Shikida e Silva, 2003).

O modelo também demonstra que os processos eleitorais foram bem distintos no que tange à probabilidade de reeleição de prefeitos. Conforme identificado na análise descrita na figura 1, no pleito de 2008 os prefeitos, em média, tiveram o dobro de chances de reeleição em comparação ao pleito de 2000, mantidos os demais fatores constantes. Finalmente, em relação aos aspectos estruturais, somente a variável populacional apresenta efeito estatisticamente significativo. Embora reduzido, esse efeito é negativo, ou seja, quanto maior a população, menores as chances de reeleição.

\section{Considerações finais}

O trabalho teve como objetivo principal aprofundar a compreensão acerca do relacionamento entre o processo eleitoral e o comportamento fiscal dos governos locais no Brasil. A temática é de suma relevância porque traz subsídios empíricos válidos para qualificar o debate acerca do instituto da reeleição e da qualidade do gasto público no Brasil. Como diferenciais, o estudo amplia o recorte temporal da literatura nacional, incluindo as quatro gestões de prefeitos municipais após 1997, o que aumenta a validade externa ou de generalização das inferên- 
cias. Ademais, analisa não apenas um único exercício financeiro, mas sim todo o mandato do prefeito. Outro aspecto importante do artigo é o olhar para além do nível de despesa, predominante na literatura doméstica. Assim, analisa a política fiscal sob diferentes dimensões arrecadação, investimentos e gastos sociais.

As evidências dos modelos estatísticos, de modo geral, são bastante interessantes. Na análise do efeito da possibilidade de reeleição sobre a política fiscal do prefeito, os resultados refutam a hipótese de que a expectativa de reeleição geraria desempenhos fiscais distintos. Uma possível interpretação é que um eventual esforço maior do prefeito em primeiro mandato também pode ser alcançado durante a segunda gestão pela experiência adquirida no mandato anterior. Além disso, o prefeito no segundo mandato, mesmo sem poder se candidatar novamente, mantém sua preocupação com a continuidade de seu partido no poder e, portanto, também se esforça na condução da política fiscal. Nesse sentido, os argumentos dos defensores da reeleição de que o mecanismo da reeleição valoriza a experiência e a continuidade administrativa ganham força.

Quanto ao impacto da gestão fiscal sobre a reeleição, os resultados são ainda mais instigantes. No âmbito da receita, os esforços do prefeito em elevar a coleta de tributos interferem negativamente nas chances de sucesso eleitoral. Do lado da despesa, a mensagem das urnas tem sido clara no que tange aos investimentos. Sob a ótica do voto retrospectivo, as estimativas do modelo confirmam a hipótese de premiação do prefeito que destina mais recursos para as obras públicas. Uma interpretação possível é que o gasto em obras públicas é mais concentrado e permite maior visibilidade dos resultados, enquanto o gasto em política social é disperso e seus efeitos são menos tangíveis no curto prazo. Isso contribuiria para a explicação do comportamento eleitoral descrito; entretanto, merece investigação futura.

Em relação aos determinantes políticos da reeleição, a pesquisa confirma o impacto da margem de vitória. Em outras palavras, o "patrimônio político" conquistado no pleito anterior importa. Esse efeito foi detectado nas variáveis de alinhamento partidário com o governador, o que reforça a percepção cada vez mais consensual de que o eleitorado vota nas eleições municipais de acordo com a conjuntura política local e menos preocupado com temas nacionais, por exemplo.

Os resultados contribuem com o debate sobre política fiscal e comportamento eleitoral. A refutação da primeira hipótese da pesquisa demonstra que a reeleição não segue uma lógica oportunista. Do mesmo modo, as evidências sobre o comportamento do eleitorado em relação à gestão fiscal constituem subsídios importantes para moldar o processo de tomada de decisões políticas. Logo, o amadurecimento da democracia pressupõe ajustes entre as preferências dos eleitores e políticos. E ainda, a comprovação do funcionamento de mecanismos de accountability eleitoral, mais especificamente do voto retrospectivo, nas eleições municipais corrobora esse processo, comum em democracias avançadas.

Vale salientar que o comportamento do eleitor não necessariamente pressupõe que todos os cidadãos conheciam a fundo as contas municipais. Contudo, mesmo assim, os resultados sugerem que, de alguma forma, o eleitor avalia o ocupante do cargo, seja pelo impacto 
direto do gerenciamento fiscal ou pelos reflexos da qualidade do gasto público nas condições de vida da população, como os efeitos de obras que tendem a impactar positivamente as chances de reeleição do prefeito.

Assim, inferências quanto à efetiva avaliação da gestão municipal por parte do eleitor e seus efeitos sobre o voto constituem-se em agenda de pesquisa bastante fértil, podendo agregar análises de outras esferas de governo, dimensões fiscais distintas, bem como estratégias metodológicas de caráter qualitativo.

\section{Referências}

AFONSO, José R.; ARAÚJO, Erika. A capacidade de gastos dos municípios brasileiros: arrecadação própria e receita disponível. In: NEVES, Gleisi et al. (Org.). Os municípios e as eleições de 2000. São Paulo: Konrad Adenauer Stiftung, 2000. p. 35-56.

AFONSO, José R.; JUNQUEIRA, Gabriel J. Investimento público no Brasil é mais municipal que federal. Revista de Administração Municipal, v. 55, n. 272, p. 18-25, out./dez. 2009.

ARAUJO JUNIOR, Ari F.; SHIKIDA, Cláudio D.; SILVA, Márcia C. Federalismo fiscal, ciclos políticos e reeleição: uma breve análise do caso mineiro. Perspectiva econômica, São Leopoldo, v. 38, n. 122, p. 5-19, 2003.

ARRETCHE, Marta et al. Capacidade administrativa, déficit e efetividade da política habitacional. Brasília: Ministério das Cidades, 2007.

BRENDER, Adi. The effect of fiscal performance on local government election results in Israel: 1989-1998. Journal of Public Economics, v. 87, n. 9, p. 2187-2205, 2003.

BRENDER, Adi; DRAZEN, Allan. Where does the political budget cycle really come from? CEPR Discussion Papers, n. 4049, 2003.

BECKER, Willian; JOHNSTON, Carol. The relationship between multiple choice and essay response questions in assessing economics understanding. Economic Record, Economic Society of Australia, v. 75, n. 2, p. 348-357, dez. 1999.

BESLEY, Timothy; CASE, Anne. Does electoral accountability affect economic policy choices? Evidence from gubernatorial term limits. The Quarterly Journal of Economics, v. 110, n. 3, p. 769-798, ago. 1995.

BESLEY, Timothy; CASE, Anne. Political institutions and policy choices: evidence from the United States. Journal of Economic Literature, v. 41, n. 1, p. 7-73, 2003.

BLOMQUIST, Willian. The policy process and large n-comparative studies. In: SABATIER, Paul (Ed.). Theories of the policy process. Nova York: Westview Press, 1999.

BOX, George E. P.; COX, David R. An analysis of transformations. Journal of the Royal Statistics Society, v. 26, n. 2, p. 211-252, 1964. 
BRASIL. Carga tributária no Brasil: análise por tributos e bases de incidência. Secretaria da Receita Federal, dez. 2013.

CARRERA-FERNANDEZ, José; PEREIRA, André L. G. A influência de transferências voluntárias na reeleição de prefeitos e no desenvolvimento dos municípios baianos. In: ENCONTRO NACIONAL DA ANPEC, 2007, Recife.

DOWNS, Antony. An economic theory of democracy. Nova York: Harper, 1957.

FERREIRA, Pedro C. Investimento em infraestrutura no Brasil: fatos estilizados e relações de longo prazo. Revista Pesquisa e Planejamento Econômico, v. 26, n. 2, p. 231-252, 1996.

FIORINA, Morris P. Retrospective voting in American national elections. New Haven, CT: Yale University Press, 1981.

IPEA. Políticas Sociais: acompanhamento e análise, vinte anos da Constituição Federal. Brasília: Ipea, 2009.

KEY JR., Valdimer O. The responsible electorate: rationality in presidential voting, 1936-1960. Cambridge, Mass.: The Belknap Press of Harvard University Press, 1966.

LANDERMAN, Laurence; MUSTILLO, Sarah; LAND, Kenneth. Modeling repeated measures of dichotomous data: testing whether the within-person trajectory of change varies across levels of between-person factors. Social Science Research, v. 40, n. 5, p. 1456-1464, 2011.

LIBÂNIO, Rita de Cássia. Indicadores sociais e desempenho nas eleições estaduais. Dissertação (mestrado) - Instituto de Pesquisas Econômicas, Faculdade de Economia, Administração e Contabilidade, Universidade de São Paulo, 2003.

MANIN, Bernard; PRZEWORSKI, Adam; STOKES, Susan. Democracy, accountability and representation. Cambridge: Cambridge University, 1999.

MENDES, Marcos; ROCHA, Carlos Alexandre A. O que reelege um prefeito? Consultoria Legislativa do Senado Federal. Textos para Discussão, n. 7, 2004.

MENDES, Marcos. Federalismo fiscal e crescimento do governo: evidências eleitorais para o Brasil. In: ENCONTRO NACIONAL DA ASSOCIAÇÃO NACIONAL DE CENTROS DE PÓS-GRADUAÇÃO EM ECONOMIA (ANPEC), XXXII, 2004, João Pessoa.

MENEGUIN, Fernando B.; BUGARIN, Mauricio S. Reeleição e política fiscal: um estudo dos efeitos da reeleição nos gastos públicos. Economia Aplicada, v. 5, n. 3, p. 600-622, 2001.

MENEGUIN, Fernando B.; BUGARIN, Mauricio S.; CARVALHO, Alexandre X. O que leva um governante à reeleição? Textos para Discussão, n. 1135, Instituto de Pesquisa Econômica Aplicada (Ipea), 2005.

NAKAGUMA, Marcos. Ciclos políticos e resultados eleitorais: um estudo sobre o comportamento do eleitor brasileiro. Dissertação (mestrado) - Instituto de Pesquisas Econômicas, Faculdade de Economia, Administração e Contabilidade, Universidade de São Paulo, 2006.

NAKAGUMA, Marcos; BENDER, Siegfried. A emenda da reeleição e a Lei de Responsabilidade Fiscal: impactos sobre ciclos políticos e performance fiscal dos estados (1986-2002). Economia Aplicada, São Paulo, v. 10, n. 3, p. 377-397, jul./set. 2006. 
NORDHAUS, William. The political business cycle. Review of Economic Studies, v. 42, n. 2, p. 169190, 1975.

NOVAES, Lucas; MATTOS, Enlinson. O efeito da intenção de reeleição sobre os gastos em saúde: uma análise com base no modelo de reputação política. Revista de Economia Política, v. 30, n. 1, p. 140-158, 2010.

PELTZMAN, Sam. How efficient is the voting market? Journal of Law and Economics, v. 33, n. 1, p. 27-64, 1990.

POWELL, George. Elections as instruments of democracy: majoritarian and proportional visions, 2000.

ROGOFF, Kenneth. Equilibrium political budget cycles. The American Economic Review, v. 80, n. 1, p. 21-36, 1990.

ROGOFF, Kenneth; SILBERT, Anne. Elections and macroeconomic policy cycles. The Review of Economic Studies, v. 55, n. 1, p. 1-16, 1988.

SAKURAI, Sérgio. Ciclos políticos nas funções orçamentárias dos municípios brasileiros. Est. Econ., São Paulo, v. 39, n. 1, p. 39-58, jan./mar. 2009.

SOUZA, Celina. Governos locais e gestão de políticas sociais universais. São Paulo em Perspectiva, São Paulo, v. 18, n. 2, p. 27-41, 2004.

\section{Legislação}

Constituição Federal do Brasil, de 10 de outubro de 1988.

Emenda Constitucional no 16, de 4 de junho de 1997.

\section{Apêndice}

\section{Tabela 3}

Estatísticas descritivas das variáveis originais dos modelos 1, 2 e 3

\begin{tabular}{|ccccccc|}
\hline Variável Original & $\mathrm{N}$ & Média & Mediana & Desvio-padrão & Assimetria & Curtose \\
\hline Arrecadação própria & 16680 & 0,057 & 0,040 & 0,052 & 2.727 & 11.183 \\
Investimentos & 16680 & 0,109 & 0,100 & 0,054 & 1.365 & 3.365 \\
Gastos sociais & 16680 & 0,646 & 0,650 & 0,096 & $-0,355$ & 0,019 \\
Margem de Vitória & 16680 & 0,183 & 0,120 & 0,205 & 2.416 & 6.286 \\
PIB & 16671 & 7229,47 & 5007,60 & 7634,84 & 4.193 & 28.691 \\
População & 16680 & 32420 & 10771 & 191863 & 3.841 & 1913,83 \\
Urbanização & 16680 & 0,620 & 0,63 & 0,23 & $-0,194$ & $-0,942$ \\
\hline
\end{tabular}

Fontes: Finbra/STN, TSE e IBGE. 
Tabela 4

Estatísticas descritivas das variáveis dos modelos 1, 2 e 3 transformadas

\begin{tabular}{|cccccccc|}
\hline Variável & Transformação & N & Média & Mediana & Desvio-padrão & Assimetria & Curtose \\
\hline Arrecadação própria & Transformed ap (lambda=0) & 16680 & 0,043 & 0,043 & 0,033 & 0,053 & 0,641 \\
Investimentos & Transformed inv (lambda=0.2) & 16680 & 0,1 & 0,1 & 0,048 & $-0,033$ & 0,4 \\
Gastos sociais & Transformed gs (lambda=1.6) & 16680 & 0,65 & 0,65 & 0,096 & $-0,096$ & $-0,282$ \\
Margem de Vitória & Log(MV) & 16680 & -2207 & $-2,12$ & 1064 & $-0,245$ & $-0,197$ \\
PIB & Log(PIB) & 16671 & 8535 & 8519 & 0,82 & 0,193 & $-0,214$ \\
População & Log(Pop) & 16680 & 9383 & 9285 & 1136 & 0,855 & 1,36 \\
Urbanização & Urb & 16680 & 0,620 & 0,63 & 0,23 & $-0,194$ & $-0,942$ \\
\hline
\end{tabular}

Fontes: Finbra/STN, TSE e IBGE.

Tabela 5

Estatísticas descritivas das variáveis categóricas dos modelos 1, 2 e 3

\begin{tabular}{|c|c|c|c|c|}
\hline \multicolumn{5}{|c|}{ Reeleito } \\
\hline & Frequência & Porcentagem & Frequência & Porcentagem \\
\hline & & & Cumulativa & Cumulativa \\
\hline $1^{\circ}$ mandato & 11573 & 69,38 & 11573 & 69,38 \\
\hline $2^{\circ}$ mandato & 5107 & 30,62 & 16680 & 100 \\
\hline \multicolumn{5}{|c|}{ Mandato } \\
\hline 1997/2000 & 5560 & 33,33 & 5560 & 33,33 \\
\hline $2001 / 2004$ & 5560 & 33,33 & 11120 & 66,67 \\
\hline $2005 / 2008$ & 5560 & 33,33 & 16680 & 100 \\
\hline \multicolumn{5}{|c|}{ Base } \\
\hline 0 & 3903 & 23,4 & 3903 & 23,4 \\
\hline 2 anos & 5692 & 34,12 & 9595 & 57,52 \\
\hline 4 anos & 7085 & 42,48 & 16680 & 100 \\
\hline \multicolumn{5}{|c|}{ Governador } \\
\hline 0 & 11323 & 67,88 & 11323 & 67,88 \\
\hline 2 anos & 3268 & 19,59 & 14591 & 87,48 \\
\hline 4 anos & 2089 & 12,52 & 16680 & 100 \\
\hline
\end{tabular}

Fonte: TSE. 
Tabela 6

Estatísticas descritivas das variáveis originais do modelo logit

\begin{tabular}{|ccccccc|}
\hline Variável Original & $\mathbf{N}$ & Média & Mediana & Desvio-padrão & Assimetria & Curtose \\
\hline Arrecadação própria & 10622 & 0,056 & 0,04 & 0,057 & 2.751 & 10.922 \\
Investimentos & 10577 & 0,117 & 0,11 & 0,061 & 1.558 & 4.413 \\
Gastos sociais & 10620 & 0,654 & 0,66 & 0,098 & $-0,353$ & 0,04 \\
Margem de vitória & 10622 & 0,157 & 0,11 & 0,177 & 2.754 & 9.364 \\
PIB per capita & 10574 & 6121,83 & 4137,95 & 6725,44 & 4.243 & 30.934 \\
População & 10622 & 27579 & 10654 & 123399 & 33,65 & 1502,33 \\
Urbanização & 10595 & 0,60 & 0,61 & 0,23 & $-0,147$ & $-0,967$ \\
\hline
\end{tabular}

Fontes: Finbra/STN, TSE e IBGE.

Tabela 7

Estatísticas descritivas das variáveis transformadas do modelo logit

\begin{tabular}{|cccccccc|}
\hline Variável & Transformação & $\mathrm{N}$ & Média & Mediana & Desvio-padrão & Assimetria & Curtose \\
\hline Arrecadação própria & $\log (\mathrm{AP})$ & 10622 & -3.288 & -3.219 & 0,963 & $-0,68$ & 2.194 \\
Investimentos & $\log (\mathrm{INV})$ & 10577 & -2.271 & -2.207 & 0,522 & $-0,385$ & 0,927 \\
Gastos sociais & $\log (\mathrm{GS})$ & 10620 & $-0,435$ & $-0,416$ & 0,161 & -1.004 & 3.069 \\
Margem de vitória & $\log (\mathrm{MV})$ & 10622 & -2.418 & -2.207 & 1,25 & -1.147 & 2,52 \\
PIB per capita & $\log (\mathrm{PIB})$ & 10574 & 8.326 & 8.328 & 0,886 & 0,034 & $-0,157$ \\
População & $\log (\mathrm{Pop})$ & 10622 & 9.358 & 9.274 & 1.103 & 0,753 & 0,982 \\
Urbanização & Urb & 10595 & 0,600 & 0,61 & 0,230 & $-0,147$ & $-0,967$ \\
\hline
\end{tabular}

Fontes: Finbra/STN, TSE e IBGE.

Tabela 8

Estatísticas descritivas das variáveis categóricas do modelo 4

\begin{tabular}{|cccccccc|}
\hline Variável & Transformação & N & Média & Mediana & Desvio-padrão & Assimetria & Curtose \\
\hline Arrecadação própria & $\log (\mathrm{AP})$ & 10622 & -3.288 & -3.219 & 0,963 & $-0,68$ & 2.194 \\
Investimentos & $\log (\mathrm{INV})$ & 10577 & -2.271 & -2.207 & 0,522 & $-0,385$ & 0,927 \\
Gastos sociais & $\log (\mathrm{GS})$ & 10620 & $-0,435$ & $-0,416$ & 0,161 & -1.004 & 3.069 \\
Margem de vitória & $\log (\mathrm{MV})$ & 10622 & -2.418 & -2.207 & 1,25 & -1.147 & 2,52 \\
PIB per capita & $\log (\mathrm{PIB})$ & 10574 & 8.326 & 8.328 & 0,886 & 0,034 & $-0,157$ \\
População & $\log (\mathrm{Pop})$ & 10622 & 9.358 & 9.274 & 1.103 & 0,753 & 0,982 \\
Urbanização & $\mathrm{Urb}$ & 10595 & 0,600 & 0,61 & 0,230 & $-0,147$ & $-0,967$ \\
\hline
\end{tabular}

Fonte: TSE. 
A análise descritiva mostra que, em geral, as variáveis numéricas originais (tabelas 3 e 6) são assimétricas, com forte peso nas caudas. Avaliando a assimetria e a curtose dos dados transformados (tabelas 4 e 7), pode-se observar que passaram a ter uma distribuição simétrica com minimização dos pesos nas caudas, principalmente, para as variáveis arrecadação própria, PIB per capita e população. As demais variáveis transformadas permitiram a linearização com respeito à variável dependente nos modelos ajustados. O desvio-padrão das covariáveis originais PIB per capita e população é bastante superior à sua média, ademais a média é bem distinta da mediana. Usando a transformação log (logaritmo neperiano na base e), a linearização passa a ser evidente (desvio-padrão inferior à média, e a mediana aproximadamente igual à média) com importante diminuição do efeito causado por casos extremos (outliers).

No caso das variáveis dependentes dos três primeiros modelos, também em função da falta de simetria (assimetria) e do peso das caudas da distribuição (curtose), utilizou-se a transformcação Box-Cox Power, olhando cada combinação de variáveis, estratificadas por UF para minimizar o efeito cluster (Box e Cox, 1964).

A covariável urbanização não necessita de transformação, o que pode ser verificado ao comparar os valores das estatísticas descritivas expostas nas tabelas anteriores. Por fim, o logaritmo aplicado também à covariável margem de vitória indicou melhor dispersão dos dados, o que justifica o uso da transformação log em relação às variáveis dependentes transformadas.

Pedro Cavalcante é professor do Programa de Pós-Graduação em Administração da Universidade de Brasília (UnB). Brasília/DF — Brasil. E-mail: pedrocavalcante@hotmail.com. 